\title{
ARTICLE
}

\section{GMO Regulation in Crisis - The Experimental Potential of Regulation (EU) 2020/1043 on Covid-19 in Addressing Both a Crisis and a Pandemic}

\author{
Special Issue Experimental Legislation in Times of Crisis \\ Sofia Ranchordás \& Bart van Klink (eds.)
}

Lonneke Poort \& Willem-Jan Kortleven*

\begin{abstract}
In this article, we analyse Regulation (EU) 2020/1043 on Covid-19 against the backdrop of the current deadlock in EU-regulation of genetically modified organisms (GMOs). We build on temporary and experimental legislation scholarship and employ a normative framework of regulatory knowledge. The Covid-19 Regulation aims at speeding up the development of GMO-based Covid-19 treatments or vaccines by temporarily suspending requirements that otherwise would have made for time-consuming and burdensome authorization processes. Although the Regulation lacks an explicit experimental purpose, we hypothesize that experiences with its functioning may be utilized in evaluation processes serving attempts to change the GMO legal framework. As such, it may fulfil a latent experimental function. We reflect on the types of knowledge that are relevant when evaluating experimental legislation and developing regulation more generally and argue that the inclusion of social knowledge is pertinent in dealing with complex issues such as GMO regulation. Experimental law literature focuses on gathering evidence-based knowledge about the functioning of legislation but virtually neglects knowledge about different experiences and value appreciations of various societal actors and social-contextual mechanisms. We propose that such social knowledge be included in the design of experimental legislation and that evaluation be approached bottom-up instead of top-down.
\end{abstract}

Keywords: experimental legislation, regulatory knowledge, GMO regulation, evaluation.

* Lonneke Poort is Associate Professor at the department of Sociology, Theory and Methodology of Law at Erasmus School of Law. Willem-Jan Kortleven is Assistant Professor at the department of Sociology, Theory and Methodology of Law at Erasmus School of Law, Rotterdam. 


\section{Introduction}

Research on genetically modified organisms (GMOs) may play a crucial role in developing medicines and vaccines against Covid-19. GMO technologies such as CRISPR-Cas9 make it relatively easy to cut and replace DNA material, and, consequently, the adaptations and changes in DNA become more accurate. Applying this technology in the development of medicines and vaccines will speed up the process and may produce better results. The contribution of GMO technologies to address this pandemic makes decision-making on authorization of clinical trials with GMOs very urgent.

Yet GMO regulation in the European Union (EU) is complex and demanding because of the interplay among and overlap between several directives and regulations on the EU level and regulatory frameworks on the level of Member States (MS). It is, therefore, not always clear which road to follow. Besides, as we show in Section 1 , even the paved roads of authorization can be rocky. This results in a time-consuming European authorization procedure for placing GMO-related products on the market (see Mampuys, 2021).

In order to abridge and simplify the authorization process for research purposes related to Covid-19, the EU issued a temporary emergency regulation (Regulation (EU) 2020/1043) that derogates from the existing legal framework. This regulation suspends the requirement for an environmental risk analysis in the case of clinical research with GMOs intended to develop Covid-19 treatments or vaccines (Arts. 2 and 3). It came into force on 18 July 2020 and will be valid for as long as the World Health Organization (WHO) declares Covid-19 a pandemic or for as long as the European Commission (EC) recognizes a situation of public health emergency due to Covid-19 (Art. 4).

In this article, we analyse Regulation (EU) 2020/1043 ('Covid-19 Regulation') in the context of GMO regulatory practice more generally, departing from a twofold theoretical perspective. First, we build on temporary and experimental legislation scholarship. The literature distinguishes between temporary legislation with and without experimental purposes. Non-experimental temporary laws are seen as particularly fit for addressing temporary issues, such as emergencies. Experimental regulations have an explicit knowledge-generating aim and are focused on temporary and/or small-scale testing of legal solutions to long-lasting problems (BarSiman-Tov, 2018; Ranchordás, 2015; Van Gestel \& Van Dijck, 2011). As an emergency measure without explicit learning purposes, the Covid-19 Regulation appears to be a mere temporary law. However, there are also arguments to conceptualize it as an experimental piece of law, especially given its potential to generate experiences and knowledge that may be utilized in attempts to change the broader GMO legal framework.

Second, we scrutinize the knowledge-generating aim that is ascribed to experimental legislation in particular by employing the concept of regulatory knowledge, as defined by Demortain (2017) and Faulkner and Poort (2017). Faulkner and Poort distinguish between three main categories of knowledge relevant for regulation: scientific knowledge, legal knowledge and social knowledge. This cate- 
gorization allows the examination of whether the understanding of knowledge common in temporary and experimental scholarship is adequate.

This brings us to the following research question: Can the Covid-19 Regulation be conceptualized as a piece of experimental legislation, and what kinds of knowledge should be taken into account to fruitfully learn from its effects?

We argue that the Covid-19 Regulation, despite its lack of an explicit experimental purpose, might turn out to be experimental in its effects since it almost naturally raises expectations for making GMO regulation more innovation friendly (cf. Wesseler \& Purnhagen, 2021). We hypothesize that the experiences with the Covid-19 Regulation will be scrutinized by a variety of stakeholders and could play a role in future attempts to soften requirements for licensing of GM products and processes on a broader scale. As such, it can be expected to fulfil a latent experimental function.

Regarding the types of knowledge that are taken into account within experimental legislation scholarship, we demonstrate that there tends to be a focus on generating knowledge about the objects to be regulated (for instance, new technologies and their potential risks and benefits) and the effects and side effects of legislation. This approximately corresponds to the categories of scientific knowledge and legal knowledge pertaining to Faulkner and Poort's (2017) conceptualization of regulatory knowledge. What is largely absent in experimental legislation theorizing, we claim, is the inclusion of the category of social knowledge. Social knowledge refers to knowledge about different experiences and value appreciations of a variety of societal actors, such as NGOs, journalists, professional communities and general public. The case of GMO regulation in the EU illustrates fairly well that this type of knowledge may considerably influence regulatory practice. The current impasse in GMO regulatory practice seems largely due to the fact that some EU MS oppose GMOs on the basis of moral considerations on 'naturalness', public attitudes and/or economic reasons, rather than because of mere scientific findings about environmental or health risks. The core of the problem seems to be that non-scientific considerations have no formal relevance in the existing legal framework (Mampuys, 2018, 2021). Hence, taking account of social knowledge seems to be a precondition for even thinking about options to break through the impasse in GMO regulatory practice.

This holds a lesson for experimental legislation more generally. Learning from experimental legislation requires that not only scientific and legal knowledge but also social knowledge is paid attention to in order to be able to adequately assess its feasibility and effectivity. To that end, we argue that learning and evaluation mechanisms pertaining to experimental legislation should be designed in such a way that they make room for diverse opinions, different meanings and understandings of the information that is gained. In other words, make more room for social knowledge. For that matter, as Millo and Lezaun (2006) argue, we may not reach consensus, or we may not find answers to the objectives of the experiment, but we can gain better insights into the problems and diverse reactions the experiment may face: making the unknown known. The latter is also acknowledged in the literature on experimental legislation (e.g. Van Gestel \& Van Dijck, 2011), but our sug- 
gestion here is to broaden the 'unknown' to come to a more comprehensive problem definition.

In the remainder of this article, we first discuss the objective and relevant characteristics of the Covid-19 Regulation in the context of the existing deadlock in GMO regulation (Section 1 ). We continue with an analysis of the literature on temporary and experimental legislation, which provides a lens to explore the nature and function of the Covid-19 Regulation in the context of GMO regulatory practice (Section 2). Subsequently, we employ the concept of regulatory knowledge in order to critically reflect on the knowledge claims being made by experimental legislation scholars, drawing specific lessons for GMO regulatory practice (Section 3). We conclude the article by pointing out some implications for temporary and experimental legislation scholarship more generally (Section 4).

\section{Regulation (EU) $2020 / 1043$ on Covid-19 and the Deadlock of GMO Regulation}

The regulation of GMOs in the EU has been marked by stagnation for decades now. This is due to complex procedures that formally take only technocratic considerations into account but do not preclude political influences, combined with the fact that the MS of the EU hold different positions on the desirability of genetic modification. For example, in the authorization procedure for cultivation of genetically modified crops (GM crops), MS have to reach a qualified majority on licensing. In regulatory practice, if a qualified majority among EU MS about licensing cannot be reached, it is up to the EC to take a decision. The EC is, however, reluctant to do so, owing to the political sensitivity of this topic. Consequently, decision-making in Europe has come to a halt and applications are piling up (Mampuys \& Poort, 2019, pp. 171-172). In the end, neither opponents who want to legally restrict cultivation nor proponents who want to cultivate GM crops can have their way. The core of the problem seems to be that even if the competent authority for risk assessment, the European Food Safety Authority (EFSA), considers a product as being safe, several MS still vote against authorization. It seems that motivations outside the legal framework, such as moral considerations on 'naturalness' and public attitudes within MS, de facto do play a role here (Mampuys, 2018).

This example shows that particularly in the context of GM crops and genetically modified food (GM food), regulation is deadlocked. Several attempts to break the deadlock have failed. An important attempt to break it was represented by Directive 2015/412, which partly decentralized GMO regulation by providing MS with the possibility to opt out for cultivation of GM crops on the basis of non-safetyrelated considerations. It was expected that GMO-critical MS would no longer vote against licensing, as their state-territory was excluded from authorization (Mampuys \& Poort, 2019). However, in licensing practice such changes did not occur (Mampuys, 2021).

In 2018, the impasse deepened when the Court of Justice of the EU (CJEU) ruled on the question whether crops (or organisms in general) that have been produced by means of new mutagenesis techniques, better known as gene editing, are subject to the obligations of European GMO rules, specifically the obligations of 
Directive 2001/18/EC on the release into the environment of GMOs (C-528/16). Several stakeholders hoped beforehand that the CJEU ruling would pave the way for a more innovation-friendly road by exempting new mutagenesis techniques from the obligations of the directive. On the contrary, the CJEU decided that these techniques are techniques of genetic modification and fall within the scope of Directive 2001/18/EC (Bergmans, Poort, Kortleven \& Kleinjans, 2020; Van der Meer et al., 2021). As a response to this ruling, the Council of the EU called for a study to offer clarity on the status of new genomic techniques. The results of this study were published in April 2021 (European Commission, 2021), identifying several knowledge gaps and limitations. The outcome of the study merely implied that future policy action was required to bridge these gaps. What kind of policy action was not specified.

MS are less divided, and hence stagnation is less intense, when it comes to authorization of medicinal products that make use of genetic modification. But here as well, complex and demanding procedures and differences between MS pose formidable obstacles to licensing genetically modified products (GM products) for medicinal use. In general, authorization for placing a medicinal product on the market in an MS of the EU is regulated in Directive 2001/83/EC and Regulation (EC) $726 / 2004$. Following these regulations, requests for written authorization should be accompanied by the results of clinical trials carried out on the product. In addition, the current GMO regulatory framework requires authorization from the competent authority of the MS in which the clinical trial for medicinal products containing or consisting of GMOs is to be conducted (Directive 2001/18/EC and 2009/41/EC). This authorization procedure involves an additional environmental risk assessment.

Thus, for placing GM products for medicinal use on the market, two authorization procedures must be followed, one focusing on health risks and the other on environmental risks. Even if these procedures work smoothly, it is a time-consuming process, not to mention the complexity of the GMO regulatory practice.

In GMO regulatory practice, environmental risk assessment and consent by the competent authority of an MS is rather complex as MS vary in their authorization procedures for clinical trials (see rec. 8 Covid-19 Regulation). Some MS require only one notification to a single competent authority per clinical trial, whereas other MS require parallel requests to several competent authorities for all conducts within the same clinical trial. Some MS apply both 2009/41/EC and 2001/18/EC, while other MS apply one of them. Besides, in the case of multi-centre clinical trials conducted in several MS, researchers need to submit requests in all of these MS (rec. 9). Researchers, then, have to follow different procedures for each MS. It is an understatement to describe it as very hard to keep track in such complex structures.

It is against this background that the Covid-19 Regulation, derogating from certain requirements of current GMO legislation, should be understood. According to the EC, the Covid-19 pandemic ensures that the EU has a major interest in making available safe and efficacious medicinal products as soon as possible (recitals 13, 14). With the Covid-19 Regulation the EC intends to facilitate, support and 
speed up the development of treatments and vaccines of the coronavirus disease by making the use of genetic modification and GMOs 'easier'.

It does so by temporarily derogating from the requirement of conducting an environmental risk assessment under Directives 2009/41/EC and 2001/18/EC: 'During the period in which the temporary derogation applies, the environmental risk assessment and consent under Directives 2001/18/EC and 2009/41/EC should not be a prerequisite for the conduct of those clinical trials.' (rec. 17). Additionally, the procedures for the use and supply of medicinal products that contain or consist of GMOs are simplified. To sum up, the Covid-19 Regulation involves that (1) only clinical trials must be pursued in light of the general authorization procedures for placing medicinal products on the markets (health risk assessment), and (2) only for manufacturing medicinal products that contain or consist of GMOs is a written authorization required.

\section{Temporary and Experimental Legislation: Theory and Practice}

\subsection{Introduction}

Since no law exists for eternity, in a very general sense every law is of a temporal nature. Yet it still makes sense to distinguish temporary legislation from ordinary legislation, the defining difference being that temporary legislation reverses the default rule regarding legislative continuity. Whereas ordinary laws remain valid unless and until legislative (or sometimes judicial) action terminates or changes them, temporary laws or temporary clauses in laws expire on a preset date, unless legislative action is taken to renew them (Bar-Siman-Tov, 2018; Gersen, 2007).

Temporary laws are seen as instruments serving better regulation or deregulation agendas. They are said to provide a means for correcting bureaucratic drift and unproductive legislative entrenchment, facilitating legislative oversight of government bureaucracies and the termination of obsolete and ineffective laws and agencies. Also, legislative change might be accepted more easily when it has a non-permanent character. Thus, temporary laws may enable legislation to keep pace with technological and societal change (Gersen, 2007; Ranchordás, 2015, 2018).

As became clear in the introduction of this article, a further distinction can be made between temporary legislation with and without experimental purposes. The latter have been used, for example, in response to single events (such as elections), crises and emergencies or other problems that are expected to be of a temporary nature (Bar-Siman-Tov, 2018; Gersen, 2007, p. 274; Oh, 2015, p. 1075; Ranchordás, 2015, 2018). By contrast, temporary legislation with explicit experimental purposes is meant to address problems that are expected to display some continuity. Despite its temporal character, it is future oriented. Its aim is to test possible solutions for a limited period and/or on a limited scale (in terms of object, addressees or (geographic) application area), in order to determine whether they should be applied on a permanent basis and a more general scale. This implies that information has to be gathered in order to be able to decide on how to follow up after an experimental measure expires. For this reason, providing for learning and evaluation mechanisms is seen in the literature as a defining characteristic of experimen- 
tal legislation (Bar-Siman-Tov, 2018; Ranchordás, 2013, 2015; Van Gestel \& Van Dijck, 2011).

Although it is possible to analytically distinguish experimental legislation from non-experimental temporary legislation, it is much more complicated to maintain this distinction in practice. This is due to a variety of factors. First, the analytical distinction itself is not entirely clear-cut everywhere in the literature. Experimental and (non-experimental) temporary measures are often dealt with simultaneously and ascribed largely similar characteristics (cf. Gersen, 2007, p. 248; Ranchordás, 2015). For instance, evaluation mechanisms are sometimes also considered a prerequisite for mere temporary laws (see e.g. Ranchordás, 2015, p. 205).

Second, political reality seems somewhat indifferent to the criteria that scholars attach to temporary and experimental law (cf. Oh, 2015). This is exemplified by the fact that in practice experimental laws often do not live up to the standards established in the literature. Bar-Siman-Tov (2018, p. 207) found in his empirical study of temporary legislation in Israel that half of temporary laws with a stated experimental purpose lacked evaluation mechanisms, and the other half contained evaluation clauses that were very basic and did not meet the criteria set in the theoretical literature. At the same time, temporary laws without a stated experimental purpose may sometimes be seen as veiled experimental laws (Ranchordás, 2013, p. 431; The Federalist Society 2011 National Lawyers Convention, 2012, pp. 342$343,358)$. Furthermore, some temporary laws in name show considerable continuity in reality, as they become routinely extended time and again (Bar-Siman-Tov, 2018, p. 202; Ranchordás, 2015, p. 218; Ranchordás, 2018, p. 17). So, considered from an empirical viewpoint, the dividing line between experimental and non-experimental legislation seems rather blurred.

Third, where evaluation mechanisms are in place, sociopolitical conditions affect the way in which evaluations are being conducted and evaluation results are dealt with, making it all but improbable that learning processes will be frustrated by defensive responses and political games (Bovens \&'t Hart, 2016; Bovens, 't Hart \& Kuipers, 2008; Gersen, 2007, pp. 274-276; Ranchordás, 2013, pp. 434-435; Van der Knaap, 2004; pp. 23-24; Van Gestel \& Van Dijck, 2011, p. 545; Visser \& Van der Togt, 2016, p. 239). Conversely, the fact that a temporary piece of legislation contains no evaluation provisions does not necessarily mean that no policy or legislative learning can or will take place.

Given the analytical affinity between experimental and non-experimental temporary legislation and the empirical difficulty of sharply distinguishing the two in practice, we provide a combined discussion of both types of temporary legislation in the remainder of this section, highlighting differences where relevant. In Section 2.2, we examine the nature and function of learning and evaluation processes in the context of experimental and non-experimental temporary legislation. In Section 2.3, we discuss the possible contribution of temporary legislation to addressing the problem that legislation tends not to keep pace with technological development. In Section 2.4, we focus on the link between temporariness of legislation and its acceptance. In Section 2.5, we evaluate the Covid-19 Regulation through the lens of temporary and experimental legislation scholarship. 


\subsection{Learning and Evaluation}

The main function of experimental legislation is considered to be 'information production'. Ranchordás (2013, p. 438) argues that experimental legislation 'converts lawmaking into a learning process, giving legislators the opportunity to try, fail, and learn from their legislative mistakes'. This process of information production and learning through trial and error does not necessarily amount to a scientific endeavour but refers to the more practical business of testing the hypothesis underlying legislation in (part of) the real world. The aim is not to produce knowledge with external validity but to gather context-specific information about the problem at hand and the effectiveness of the new law. There is a comparative element to this. The information gained by a legislative experiment should help lawmakers in deciding whether the tested rules would more adequately address the regulated object than the existing rules did or could do (Ranchordás, 2013, pp. 426-427).

We witness a paradox here. Having no other pretension than producing knowledge whose validity is limited to a specific legislative context, experimental legislation appears to be a more modest instrument than other evidence-based lawmaking instruments that rely on state-of-the-art scientific knowledge (cf. Van Gestel \& Van Dijck, 2011, p. 546). At the same time, it is more ambitious in that it provides for specific empirical knowledge about law in action before a permanent law is enacted. As such, it combines advantages of ex ante and ex post evaluations. This can be considered more valuable for improving law than whatever form of scientific knowledge is produced in advance, which at best allows for modelling possible effects.

This is not to deny that the information gained by evaluating the effects of a legislative experiment will necessarily have certain shortcomings. Since legislative experiments tend to be conducted on a limited scale and for a limited period (Van Gestel \& Van Dijck, 2011, p. 542), they leave open the question as to the extent to which the results can be extrapolated to a more general scale and whether all effects the new rules would have produced when enacted for a longer period have already become visible by the end of the experiment (cf. Klein Haarhuis \& Niemeijer, 2009, pp. 405, 412-413). In addition, the very temporariness of a measure may affect its effects, because rule addressees may act differently from the way they would have done if the measure had a permanent character (Gersen, 2007, pp. 277278).

Notwithstanding these limitations, the information gained by experimental legislation may serve an important function, especially when initial uncertainty is high. In such contexts, for instance surrounding emerging technologies and new risk problems, experimental legislation offers more flexibility than conventional laws can provide. It allows for a rapid response that enables postponing the decision on how to finally regulate the problem until more knowledge is available, while simultaneously contributing to the required knowledge base (Gersen, 2007, p. 278; Ranchordás, 2013, p. 427).

Whereas learning and evaluation are clearly associated with experimental legislation, it is less evident which role learning and evaluation (should) have, if any, in the case of temporary legislation that is not explicitly experimental. There is empirical ground to assume that most temporary legislation without an experi- 
mental aim does not provide for learning and evaluation mechanisms (Bar-SimanTov, 2018, p. 207). Moreover, the observation that non-experimental temporary laws are fit for dealing with issues characterized by limited time horizons (BarSiman-Tov, 2018; Ranchordás, 2015) seems to suggest that there is no, or at least less, need for learning.

Like Gersen (2007) and Oh (2015) emphasize, however, even without an experimental purpose there is a natural link between temporary legislation and the generation of new information. To start with, a lack of information may be a reason for enacting temporary rather than permanent legislation. This makes it easier to adapt legislation once there is more information available (see also Ranchordás, 2015). The need for new information becomes urgent when a temporary law is about to expire, because then the question as to how the regulated object should be dealt with after the expiry date must be answered. Ideally, this question is answered on the basis of new information on the object of regulation and the effects of the regulation. For this reason, Ranchordás (2015, p. 217-218) states that sunset clauses usually provide for a final evaluation.

This claim appears to be of more of a theoretical than an empirical nature, considering Bar-Siman-Tov's findings, which suggest that in practice temporary legislation tends to lack proper evaluation mechanisms. It is likely that decisions about whether or not to renew temporary legislation are often based on evaluative moments that occur despite the lack of formal evaluation provisions. Consequently, such decisions can be expected to have a more volatile, incomplete and/or political character than temporary legislation theorists would have it (cf. Bovens et al., 2008; Gersen, 2007; Oh, 2015).

\subsection{Addressing the Pacing Problem}

In a context of accelerating technological innovation, law tends to lag behind. Lawmakers have insufficient information and face too much complexity to be able to readily address new phenomena, have other priorities or are inhibited by legal safeguards, legal entrenchment or political stalemate. Whereas some lagging behind need not be problematic and seems unavoidable, the gap between technological and legal development must remain limited lest laws run the risk of becoming inadequate and irrelevant (Marchant, 2011; Ranchordás, 2015, 2018).

Temporary and experimental legislation is seen as a possible remedy to this pacing problem, owing to its abilities to generate useful information, to bridge the period needed for gathering information and to facilitate smoother adaptation of existing legislation (Gersen, 2007, p. 278; Marchant, 2011 p. 29; Ranchordás, 2013, 2015, 2018). Thus, as Ranchordás emphasizes, temporary and experimental legislation could contribute to fostering an innovation-friendly environment. Temporary instruments may help to better adjust legislation to the 'life cycles' of innovations and, through less time-consuming procedures and easier elimination of obsolete rules, can reduce regulatory burdens (Ranchordás, 2015, p. 203, 215, 218-219).

Conversely, temporary and experimental laws may also have a role in timely imposing restrictions to innovations that are likely to produce negative side effects. Since technologies tend to grow more resistant to regulatory influence as 
they develop and become embedded in society, it is important that lawmakers act at an early stage in order to be able to exert some control over the evolution of a technology (Moses, 2007, pp. 248-249; Moses, 2013, pp. 7-8). The uncertainty paradox inherent in early regulatory action (action is needed, but too little is known for deciding on the proper action; cf. Moses, 2013, p. 8) can be better dealt with by temporary instruments than by conventional legislation.

\subsection{Temporary and Experimental Legislation as Consensus-Finding Instruments}

Part of the reason why temporary legislation, both experimental and non-experimental, is expected to speed up the legislative response to technological and societal change, is its supposed potential for facilitating consensus. In the literature on temporary legislation, it is hypothesized that reaching political consensus on a piece of law will be easier (or less challenging) and therefore less time-consuming when the law is temporary instead of valid for an indefinite period. Maltzman and Shipan (2008) observe that especially in a context of divided government, sunset clauses are used to persuade political actors into supporting a new law (cf. also BarSiman-Tov, 2018; Gersen, 2007).

From the literature at least two explanations can be distilled for the hypothesized link between temporariness of legislation and the probability of its political acceptance. First, because of the temporariness of a measure, political actors retain control over its future and have the option to let it 'die' after a fixed period. It also allows for postponing a more definite decision on the problem at hand. This lowers the threshold for supporting a piece of law. Despite doubts or objections, political actors may be more willing to give a measure 'a chance' if it is 'only' temporal (Gersen, 2007; Ranchordás, 2015, 2018).

Second, it is argued that the information generated about the effects of a temporary measure may function as an evidence-based check on the assumptions and intuitions held by political actors. If certain ideas about the workings of a temporary law prove to be ill-founded, political actors would be willing to revise these ideas in light of the new information. Conversely, if a measure turns out to be ineffective or results in unwanted consequences, it can be more easily revised or be allowed to expire. In this way, temporary legislation, especially when containing evaluation provisions, encourages political actors to adhere to empirically established findings, which would simultaneously lead to bridging or reducing ideological differences (Ranchordás, 2013, 2015, 2018; Van Gestel \& Van Dijck, 2011). Van Gestel and Van Dijck even point to the possibility that political actors channel ideological disagreement by committing themselves beforehand to the outcomes of a legislative experiment. This would mean that they either specify in advance which policy consequences certain outcomes should have or assign independent decision makers the task of drawing policy consequences from the outcomes (Van Gestel \& Van Dijck, 2011, p. 547).

The second explanation seems to be more idealistic than the first. The basic assumption seems to be that political and ideological differences of opinion may become smaller or less important once uncertainties and lack of knowledge are reduced. This could be the case to a certain extent and seems partly dependent on political structure and culture, but overall, the assumption seems a bit naïve. Polit- 
ical and ideological differences of view tend to be rather resilient to rectification on the basis of empirical findings. Political actors may simply ignore or downplay unwelcome findings or take advantage of the complexity and ambiguity of the information about the effects of legislation (Bovens \&'t Hart, 2016; Bovens et al., 2008; Gersen, 2007, pp. 274-276; Ranchordás, 2013, pp. 434-435; Van der Knaap, 2004, pp. 23-24; Van Gestel \& Van Dijck, 2011, p. 545). After all, such information often allows for different interpretations, particularly in the case of 'wicked problems' (cf. Klein Haarhuis \& Niemeijer, 2009; Van Twist, Kort \& Van der Stee, 2015). The way GMOs are being dealt with in the EU is a case in point, as we will further discuss in Sections 2.5 and 3.3. In this field, facts could not trump ideological and political differences. Despite the generation of a wealth of knowledge about the properties of GMOs and the effects of GMO legislation, the lack of consensus within and between EU MS on the issue of GMO regulation has been remarkably persistent (cf. Mampuys, 2021).

\subsection{The Covid-19 Regulation Through the Lens of Temporary and Experimental Legislation Scholarship}

When we examine the Covid-19 Regulation through the lens of the literature on temporary and experimental legislation, we need to distinguish between two levels. First, the Regulation as such and, second, the Regulation as part of and derogating from the wider EU GMO regulatory framework, or even as an event in the history of GMO regulatory practice in the EU.

At the first level, we must soon conclude that the Covid-19 Regulation is largely a textbook example of temporary legislation without experimental pretensions. The Regulation's main goal is to address an emergency. It has a sunset clause. Interestingly, its sunset is not at a preset date but made dependent on the end of the emergency, as defined by an external body, the WHO or the EC. The Regulation does not contain evaluation provisions. This can easily be explained with reference to the aim of this regulation, which is simply to facilitate addressing the current pandemic as adequately as possible. The EU legislative actors do not seem to intend to 'learn' or gain more knowledge to improve regulation.

This picture becomes a bit more complicated if we consider that the means to the end of addressing the pandemic is innovation, which may be unusual compared with other temporary laws addressing emergencies. The Covid-19 Regulation provides for a derogation from existing legal requirements that is limited in terms of time and object, removing regulatory barriers in order to facilitate research on and development of new vaccines and medicines. Hence, although the Regulation does not aim at production of knowledge about its own functioning, it stimulates a specific form of knowledge production that is instrumental to its aim of remedying the pandemic.

The Covid-19 Regulation nicely illustrates the claims made in the literature about temporary legislation's abilities to address the pacing problem. It does so in two ways. First, the legislative process establishing the Regulation was unusually swift, taking only a few months. Whereas some MS within the EU are known as anti-GMO and vote almost automatically against authorization of GM products, 
almost all MS were on board with this temporary measure. ${ }^{1}$ Second, the Regulation itself cuts down the period needed for authorization by suspending the requirement of environmental risk assessment. This makes the Regulation an example of temporary legislation that is innovation friendly and contributes to addressing the pacing problem.

This case also resonates with the literature on temporary legislation's potential for facilitating consensus. The first explanation discussed in Section 2.4 seems to apply here. The fact that the Regulation only temporarily and for a circumscribed group of products derogates from the GMO regulatory framework has lowered the threshold for support and is likely to have played a role in the Regulation's ready acceptance by a qualified majority of MS, among which are GMO-critical MS. Of course, another important factor is the urgent need felt in every MS to mitigate the impact of the pandemic.

When we turn to the second level of analysis, considering the Covid-19 Regulation in the context of the EU GMO regulatory framework and its history of contestation and stalemate, there is ground to take resort to the concept of experimental legislation. Although the Covid-19 Regulation lacks important characteristics of experimental legislation, we argue that it might turn out to be experimental in its effects since it almost naturally raises expectations for breaking through the current deadlock in GMO regulation. Companies, scientists, interest groups and some EU MS favouring or involved in genetic modification have long been advocating for an environment that is less discouraging to GMO-related innovation. They yearn for change of EU regulatory practice and seize on every opportunity that might be instrumental in bringing about change. As we discussed in Section 1, they hoped in vain that the CJEU would force GMO regulation into a more innovation-friendly direction. Now they will probably project their hopes onto the Covid-19 Regulation: if regulatory barriers can be lowered to deal with a pandemic, why not to address other pressing needs and societal challenges? (cf. Wesseler \& Purnhagen, 2021). The recent EC study on new genomic techniques may also be seen as partially catering to these hopes (European Commission, 2021). However, the outcomes of the study did not result in any concrete policy advice and actions.

Hence, despite the absence of formal data generation purposes and evaluation mechanisms, we believe that the experiences with the Covid-19 Regulation will be scrutinized by a variety of stakeholders and could play a role in future attempts to soften requirements for licensing of GM products and processes on a broader scale. In terms of functionalist thought, this Regulation lacks a manifest experimental aim but can be expected to fulfil a latent experimental function (cf. Merton, 1957, pp. 40-41).

If so, the effects and possible side effects of the Regulation would be evaluated, not formally but in a scattered way, by different stakeholders and observers, using different methods with various degrees of thoroughness, departing from different

1 With only abstentions from the Netherlands and Czech Republic, the Regulation was adopted with a qualified majority of 25 MS. www.consilium.europa.eu/en/general-secretariat/corporate-policies/ transparency/open-data/voting-results/\# (accessed on 14 January 2021). 
perspectives and driven by different motives. Some EU MS might later try to initiate a formal evaluation as well. The outcomes of such a variety of evaluations would probably be ambiguous, partly incompatible and partly poor-quality but, taken together, could also highlight aspects that would be underexposed or lacking in a formal evaluation and provide better insight into societal considerations and different value appreciations.

In the next section, we delve deeper into the question of what types of knowledge are worth pursuing when evaluating temporary legislation that is manifestly or latently experimental. To this end, we employ and explain the concept of regulatory knowledge that intends to offer a comprehensive instrument to understand the varietal types of knowledge that may be relevant for lawmaking. We draw some lessons specific to the field of GMO regulation.

\section{Regulatory Knowledge}

\subsection{Introduction}

Regulatory knowledge is a concept that has had various meanings over the years, denoting, for instance, the knowledge about rules and their enforcement (specifically in sociolegal studies: Bardach \& Kagan, 1982; Hutter, 1997; Levi \&Valverde, 2001). As Demortain (2017) explains, regulatory knowledge has also been used, albeit sporadically, to cover the knowledge practices of scientists being relevant for lawmaking (Jasanoff, 2012). The latter merely refers to what was earlier called regulatory science: scientific knowledge that is needed to make regulatory decisions. In Science and Technology Studies, regulatory science has been strongly criticized as it cannot deal with uncertainties and controversies, when focusing only on scientific knowledge. Furthermore, it only includes politicians and scientists in constructing the object for regulatory intervention.

Regulatory knowledge in terms of Demortain covers more, being 'potentially very diverse regulatory knowledge, understood in just this manner as the ensemble of experiences, value appreciations and information that construct an object for regulation and legitimize regulatory intervention' (Demortain, 2017).

Following the latter definition, both regulatory science and experiential or social knowledge are part of this diverse conception. Consequently, it is not only scientific experts and politicians who are relevant stakeholders for lawmaking, but a variety of social actors such as NGOs, journalists, public and professional communities are motivated to circulate knowledge too (Demortain, 2017). Faulkner and Poort (2017) continued to develop the concept of regulatory knowledge by exploring the types of knowledge relevant for choosing a regulatory strategy in addressing novel technologies. Building on outcomes of comparative studies, they have identified additional sources of knowledge that can be relevant for lawmaking, such as ethics, economic knowledge and procedural knowledge about the 'rules of the game' of political processes of decision-making. The latter refers to knowledge of political procedure, the legal culture, the legal system and of the position of legal principles ((legal knowledge) Faulkner \& Poort, 2017). As they show by their case studies, the way a national state embeds (breaking, stretching or maintaining the legal framework) novel technologies depends on the characteristics of its legal sys- 
tem and legal culture (Faulkner \& Poort, 2017). The legal system and legal culture influence the legal categorizations that build that legal system, but also the role that other types of knowledge such as 'ethics' can play in it.

In a different context (nanotechnology), Stokes (2012) argued that using ill-suited regulatory frameworks may result in difficulties as the regulation of the new technology inherits all aspects of the existing regulatory framework. Here too legal knowledge becomes relevant. Inherited regulation, its legal basis and its broader context of values, goals and intentions are part of legal knowledge that all appear relevant for lawmaking.

In this article we use this framework in a normative way to understand what types of knowledge are relevant for making better regulation in complex issues such as genetic modification that are characterized by uncertainties and controversies. We follow Faulkner and Poort in distinguishing three main categories, namely scientific, social and legal knowledge. In the following, we use this threefold distinction to elaborate on the different strands of knowledge that are 'produced' in the experimental legislation paradigm and on the question of what kinds of lessons need to be learned in the context of GMO regulation.

\subsection{Regulatory Knowledge in Experimental Legislation}

As we have seen in Section 2, knowledge and knowledge production provide a main function of experimental legislation. The understanding of knowledge, here, touches on all three categories of regulatory knowledge, as described above. First of all, the central idea behind experimental legislation is to improve the evidence base of regulation by producing empirical knowledge about the effectivity of specific rules. Although this does not necessarily amount to a scientific endeavour in a strict sense and is distinguished by experimental legislation scholars from the conventional way of producing (abstract) scientific knowledge, the empirical knowledge produced by experimental legislation may certainly be seen as 'scientific knowledge' in terms of the regulatory knowledge paradigm. Second, experimental legislation promises to reach consensus among political actors more easily. Here, it touches on social knowledge. And, third, the relevance of legal knowledge seems to be acknowledged in the search for better regulation. Legal principles as such are part of the analysis of experimental legislation scholars and their exploration of what better regulation is. In the following, we elaborate on how these types of regulatory knowledge connect to experimental legislation theory and in doing so lay bare certain shortcomings of the latter.

In their claims in the context of better regulation, experimental legislation scholars have criticized the classic understanding of regulatory science. Van Gestel and Van Dijck (2011) emphasize that regulatory science only builds on existing data and expertise and is lacking connection to current and future practice. They argue, together with other experimental legislation scholars, that the empirical experimental setting that experimental legislation creates provides more adequate evidence-based knowledge to constitute better legislation. Their knowledge claims include evidence-based knowledge, context-specific information about the problem at hand and knowledge about the effectivity of the new rules. As we have seen in Section 2.2, evaluations play an important role in gathering this information. 
Evaluation establishes a learning process concerning the mechanisms that work and those that do not. Besides, the combination of ex ante and ex post evaluations contributes to improving laws by gaining knowledge about the functioning of rules in a specific context.

Yet, in experimental legislation theory, the focus is on testing the legislative hypothesis (see Section 2.2). This apparently implies employing a traditional topdown approach of evaluation, which tends to be preoccupied with those effects that the rules intend to produce (cf. Klein Haarhuis \& Niemeijer, 2009; Van Twist et al., 2015). The question for evaluation may be extended by 'what can be measured within the context', but still focuses on the 'what' (Kerseboom, 2008). In topdown approaches to evaluation there seems hardly any room for the 'why', setting aside value appreciations, social-contextual factors and general 'field' experiences that can be discovered when following a broader bottom-up perspective (Van Twist et al., 2015).

As for gathering social knowledge, Van Gestel and Van Dijck (2011) as well as Ranchordás (2015) claim that experimental legislation contributes to consensus-finding as opponents are more willing to accept regulations that have a temporary status (see Section 2.4). Here, however, the conception of proponents and opponents that need to reach consensus is defined from a narrow political perspective, representing only those actors playing a role within the political spectrum of decision-making. Besides, consensus-finding builds on the assumption that facts may trump ideological differences. The scientific knowledge gained during the legislative experiments functions as 'evidence' to check the assumptions and intuitions of those political actors. The broader societal conception, including the general 'field' experiences and value appreciations of non-political actors, is not explicitly considered within this line of thought.

And last, Van Gestel and Van Dijck (2011) touch on the role that legal knowledge plays in their understanding of experimental law by pointing at specific legal problems that come along with testing new legislation on a small scale. They refer to the reconcilability with principles such as equal treatment and legal certainty (see also Ranchordás, 2013). Opponents of legislative experiments fear infringement of those principles (see also Philipsen, Stamhuis \& De Jong, 2021). Following the framework of Faulkner and Poort, these legal principles are part of the legal knowledge setting the scene for legal decision-making. In this context, Van Gestel and Van Dijck (2011) emphasize that 'legislative experiments should always be justifiable and embedded in a legislative framework providing the conditions the experiment needs to meet' (p. 553). To that extent, legal certainty can be ensured. They also draw interesting conclusions on legal transplants as experimental legislation may prevent transplantation of rules and regulations without considering its consequences. By use of legislative experiments, too easy transplants can be stopped. Here, we can recognize similar claims as made by Stokes on ill-suited legal frameworks and inherited regulation (see Section 3.1). Although not explicitly emphasized, it seems that experimental law scholars have an eye for both including and producing legal knowledge.

To sum up, experimental legislation theory seems to have some affinities with the concept of regulatory knowledge, most particularly with regard to the catego- 
ries of scientific knowledge and legal knowledge. Its understanding of knowledge, however, is rather narrow when it comes to including the 'unknown'. Evaluation is conceptualized as focused predominantly on preset legislative aims and assumptions (the 'legislative hypothesis'). This might well lead to disregarding bottom-up knowledge on 'why' things do or do not work. Relatedly, experimental law theorists fail to explicitly recognize the need to include broader societal conceptions of the problem at hand in the evaluation process. As we will explain in the next section, it is such broader societal conceptions that complicate the functioning of the GMO legal framework in the EU.

\subsection{Lessons to Be Learned in GMO Regulation}

In this section, we explore whether examining the Covid-19 Regulation in action through the lens of experimental legislation may offer knowledge that can contribute to breaking the deadlock in GMO regulation (see also Wesseler \& Purnhagen, 2021). Although some valuable lessons can be learnt, we will show that the practice of GMO regulation needs the inclusion of more strands of knowledge than current experimental legislation literature promises.

To start with, we do consider the 'evidence' that can be provided by experimental legislation about the effectivity as valuable. One of the complexities in GMO regulation is caused by the time-consuming authorization procedure. 'Experiments' such as the enactment of the Covid-19 Regulation may provide relevant experiences with reducing the time span of procedures while guaranteeing risk assessment. It is entirely possible that these experiences may also set the scene for speeding up the authorization procedures in general.

In the context of the Covid-19 pandemic, EU MS were almost unanimously willing to accept the temporary measure to speed up authorization. In the case of this emergency a consensus was reached. Here, consensus seems to be in line with the first pragmatic explanation for a relationship between political acceptance and temporariness of law (see Section 2.4). But we have our doubts about whether this will also influence and bridge the more ideological differences (cf. discussion of second explanation in Section 2.4) and, consequently, whether it will do the trick in changing the voting behaviour of all MS.

To be sure, the achievements with the use of GMO technology in finding a treatment or vaccine for Covid-19 will convince some actors who were initially opposed to genetic modification out of fear of the unknown or worries for the future. As we have seen, however, several opponents have different motivations (Mampuys \& Brom, 2015; Millo \& Lezaun, 2006). For some opponents of GMO regulation, it is obviously not about risk perception and safety (Mampuys, 2018). Mampuys and Poort (2019) have shown that in current GMO licensing practice, MS tend to vote against licensing, even when the use of GMOs is considered safe by the EFSA. Other strands of knowledge play a role in their deliberation, such as value-laden appreciations, public attitudes towards naturalness or socioeconomic and political interests (Mampuys \& Brom, 2015). In terms of knowledge claims, relevant social knowledge not only contains shared societal conceptions building on consensus but also involves insights into ideological differences and value appreciations (Poort, 2013). 
It is hard to evaluate whether the 'effect' of speeding up the procedure can establish a long-term social process of changing voting behaviour, especially when evaluation is merely restricted to the 'what' (see Sections 2.2 and 3.2). As we saw in Section 2.2, the temporariness of a law may affect its effects. Klein Haarhuis and Niemeijer (2009) commented on the practical pitfalls of the experimental tradition of evaluation in the following terms:

the establishment of the net (end) effects of an intervention or programme is key ... However, such a design is characterized by practical pitfalls, particularly in the case of laws, which require a complex and long-term social process before being able to distinguish effects.

Klein Haarhuis and Niemeijer plead for evaluation on the basis of the question 'why it works' together with 'in which context'. Therefore, additionally, knowledge about mechanisms of social context need to be gathered. Regulators need to balance different types of knowledge that cannot be reduced to each other. Let us explain that by an example of GMO regulatory practice.

Millo and Lezaun analysed a regulatory experiment on farm-scale experiments in the UK in which the British government tested the effects of GMOs on farmland biodiversity in a restricted area of the UK. During the trials, the UK agreed to put authorization on hold (Millo \& Lezaun, 2006). The experiment was premised on a narrow conception of the relevance of knowledge, relying heavily on scientific knowledge: 'As soon as we know more about the technology, and we inform all actors, we will all come to an agreement.' Yet Millo and Lezaun show that most critics of both biotechnology and the experiment emphasized that the experiment was 'an unacceptable abdication of the fundamental ethical and political debate that ought to guide such a decision' (Millo \& Lezaun, 2006, p. 183). Millo and Lezaun concluded that the scientific trials did not bring about any consensus among opponents and proponents as both used (different) pieces of the evidence to support their previous claims (Millo \& Lezaun, 2006). Millo and Lezaun refer here to an experimental gap as not all evidence can be gathered within the experiment that may be relevant for decision-making or defining the regulatory status of GMOs. You cannot build decisions on the regulatory status of GMOs 'on a test that did not evaluate their impact' (Millo \& Lezaun, 2006, p. 183).

We do see the potential of experimental law also for GMO regulation but doubt its promises to reach consensus in the long run by resolving ideological differences (cf. Van Gestel \& Van Dijck, 2011). Hence, if we really want to establish the effects of breaking through this part of the deadlock, by use of experimental legislation, we must recognize that a broader understanding of social knowledge is equally important to scientific knowledge in coming to better regulation. Regulation is, at least to a certain extent, dependent on political decision-making that encloses more than the scientific context (Mampuys, 2021). Regulators therefore need to consider that there may be different views on the desirability of an innovation and that these views may be informed by considerations other than merely the perceived risks of the innovation. An innovation may be seen, for instance, as undesirable because of an unequal distribution of economic benefits (reaped by a few) and 
costs and externalities (borne by society as a whole or specifically disadvantaged communities). Or people may feel that a new technology encroaches too far into 'the natural order of things'. Regulators or innovators may tend to think that these considerations are irrelevant or even irrational (which can be argued to be an ill-founded view), but they have no choice than to treat them as relevant.

In the last section, we conclude by reflecting more generally on the role of social knowledge in evaluation processes pertaining to temporary and experimental legislation.

\section{Implications for Temporary and Experimental Legislation}

In this article, we have analysed the Covid-19 Regulation against the backdrop of the temporary and experimental law literature and a normative framework of regulatory knowledge. We have approached the Covid-19 Regulation as a temporary piece of law with a latent experimental function, meaning that various stakeholders might want to draw lessons from the experiences with this Regulation, especially its abilities to achieve consensus among EU MS and to speed up authorization processes. Whether these experiences and lesson-drawing are likely to actually contribute to breaking the current deadlock in GMO regulation may be doubted, but we have argued that any solution needs to at least take account of social knowledge, such as knowledge about public perceptions, value appreciations and general field experiences. These have turned out to be crucial factors in the field of GMO regulation, obstructing complexity-reducing attempts at regulating GMOs by considering merely scientific and legal aspects.

We suggest that social knowledge is also highly relevant in regulating other problems, especially wicked ones, characterized by both uncertainty and ambiguity. This has an implication for temporary and experimental legislation more generally. In thinking about and shaping learning and evaluation mechanisms in the context of temporary and experimental legislation, efforts should not be limited to testing top-down legislative hypotheses and generating knowledge about characteristics of (for instance) new technologies and intended and unintended effects. It should also be directed to knowledge about public attitudes to and perceptions of new technologies and knowledge about the ethical acceptability and desirability of such technologies. The field trials with GM crops analysed by Millo and Lezaun (2006) illustrated that a narrow conception of knowledge, focusing only on scientific investigation of the properties of the regulated object, failed to address the core of societal debate. Regulation of new technology is (or should be) more than a merely technocratic effort to pick the fruits of innovation while avoiding serious risks. To quote Mayer (1999),

misusing science to obstruct democratic questioning of GM crops; hiding behind a set of scientific experiments to avoid the debate and all its complexities is neither rigorous science nor good governance. (see also Millo \& Lezaun, 2006, p. 183) 
In the experimental design, questions on the 'consequences and attractiveness of one or more policy options' (Bobrow \& Dryzeck, 1987, p. 5) need to be included. For example, the design may include the public responses to certain trials or policy decisions. We acknowledge that 'knowing' more about the diversity of public attitudes and the ethical acceptability will not automatically or necessarily result in consensus (see also Poort, 2013, chapter 10). But the experimental design should give room to broadening and channelling these different strands of social knowledge.

Making these strands part of the legal experiment may contribute to bridging the experimental gap (Millo \& Lezaun, 2006) or at least reduce the gap. As for that matter, the legal experiment can generate unexpected data, explicate new questions that come up and make uncertainties more amenable (Millo \& Lezaun, 2006). Here, the role of evaluation in the legal experiment becomes prominent, for it can create a moment to actually learn from the experiment. It is, therefore, the framework for evaluation that can facilitate broadening of framing. Instead of following a top-down evaluation approach, we argue that following a more grass-roots or bottom-up approach may broaden the experimental design. According to Klein Haarhuis and Niemeijer, the 'chains of events' set in train by legislative interventions should be evaluated 'not simply as a result of laws as such, but as a product of their social, economic or cultural context' (Klein Haarhuis \& Niemeijer, 2009, p. 406).

Of course, including social knowledge in the design of experimental legislation would presuppose that it features a proper evaluative framework, which according to Bar-Siman-Tov (2018) tends to be lacking in practice. There is a gap between theory and practice that needs to be reduced. Given the reality of political and societal interests, practice can be expected, at most, to offer a rather modest contribution to reducing the gap. Hence, it is perhaps theory that should display some flexibility and move closer towards practice. To this effort we have contributed by adding the concept of latent experimental legislation to the analytical toolbox. This concept renders visible the idea that legislation need not have a manifest experimental purpose to be experimental in its effects. Even when an evaluative framework is absent, learning and evaluation may take place. This might amount to a messy and scattered variety of learning and evaluation processes, initiated bottom-up by different actors with partly incompatible perspectives and interests. Yet, for all its disadvantages, this very representation of different perspectives could have one major advantage. It potentially increases the visibility and perceived relevance of the category of regulatory knowledge that is currently most undervalued: social knowledge.

\section{References}

Bardach E. \& Kagan, R. A. (1982). Going by the book: The problem of regulatory unreasonableness. Philadelphia, PA: Temple University Press.

Bar-Siman-Tov, I. (2018). Temporary legislation, better regulation and experimentalist governance: An empirical study. Regulation and Governance, 12(2), 192-219. 
Bergmans, H., Poort, L. M., Kortleven, W. J. \& Kleinjans, R. (2020). Uitspraak van het Europees Hof over gene-editing en de ggo-regelgeving: Reikwijdte en consequenties. COGEM onderzoeksrapport CGM 2020-03.

Bobrow, D. S. \& Dryzeck, J. S. (1987). Policy analysis by design. Pittsburgh, PA: University of Pittsburgh Press.

Bovens, M. \& 't Hart, P. (2016). Revisiting the study of policy failures. Journal of European Public Policy, 23(5), 653-666.

Bovens, M., 't Hart, P. \& Kuipers, S. (2008). The politics of policy evaluation. In M. Moran, M. Rein \& R. E. Goodin (Eds.), The Oxford handbook of public policy (pp. 319-335). Oxford: Oxford University Press.

Demortain, D. (2017). Expertise, regulatory science and the evaluation of technology and risk: Introduction to the special issue. Minerva, 55(2), 139-159.

European Commission (2021). Study on the status of new genomic techniques under Union law and in light of the Court of Justice ruling in Case C-528/16. Commission staff working document. Brussels: European Commission.

Faulkner A. \& Poort, L. M. (2017). Stretching and challenging the boundaries of law: Varieties of knowledge in biotechnologies regulation. Minerva, 55(2), 209-228.

Gersen, J. E. (2007). Temporary legislation. University of Chicago Law Review, 74(1), 247298.

Hutter, B. (1997). Compliance: Regulation and environment. Oxford and New York: Oxford University Press.

Jasanoff, S. (2012). The practices of objectivity in regulatory science. In Ch. Camic, N. Gross, \& M. Lamont (Eds.), Social knowledge in the making (pp. 307-338). Chicago, IL and London: University of Chicago Press.

Kerseboom, J. (2008). Leren van evalueren: Over het niet-gebruik van beleidsinformatie. Bestuurskunde, 17(2), 41-46.

Klein Haarhuis, C. M. \& Niemeijer, E. (2009). Synthesizing legislative evaluations. Putting the pieces together. Evaluation, 15(4), 403-425.

Levi, R. \& Valverde, M. (2001). Knowledge on tap: Police science and common knowledge in the legal regulation of drunkenness. Law \& Social Inquiry, 26, 819-846.

Maltzman, F. \& Shipan, C. R. (2008). Change, continuity, and the evolution of the law. American Journal of Political Science, 52(2), 252-267.

Mampuys, R. (2018). Socio-economic considerations in regulatory decision-making on GM crops. Collection of Biosafety Reviews, 10, 8-34.

Mampuys, R. (2021). The deadlock in European GM Crop Authorizations as a wicked problem by design: A need for repoliticization of the decision-making process (Dissertation, Erasmus School of Law, Rotterdam, Chapter 9).

Mampuys, R. \& Brom, F. W. A. (2015). Ethics of dissent. A plea for restraint in the scientific debate about the safety of GM crops. Journal of Agricultural and Environmental Ethics, 28(5), 903-924.

Mampuys, R. \& Poort, L. M. (2019). Controversy first: Factors limiting the success of Directive (EU) 2015/412 for national decision-making on the cultivation of GM crops. Journal of Law, Innovation and Technology, 11(2), 175-202.

Marchant, G. E. (2011). The growing gap between emerging technologies and the law. In G. E. Marchant, B. R. Allenby \& J. R. Herkert (Eds.), The growing gap between emerging technologies and legal-ethical oversight: The pacing problem (pp. 19-33). Dordrecht/Heidelberg/London/New York: Springer.

Mayer, S. (1999). Science's secret garden. The Financial Times, 5 August.

Merton, R.K. (1957). Social theory and social structure. New York: Free Press.

Millo, Y. \& Lezaun, J. (2006). Regulatory experiments: Genetically modified crops and financial derivatives on trial. Science and Public Policy, 33(3), 179-190. 
Moses, L. B. (2007). Recurring dilemmas: The law's race to keep up with technological change. University of Illinois Journal of Law, Technology \& Policy, 2, 239-286.

Moses, L. B. (2013). How to think about law, regulation and technology: Problems with technology as regulatory target. Law, Innovation and Technology, 5(1), 1-20.

Oh, J. S. (2015). The pivotal politics of temporary legislation. Iowa Law Review, 100(3), 1055-1104.

Philipsen, S., Stamhuis, E. F. \& de Jong, M. (2021). Legal enclaves as a test environment for innovative products: Toward legally resilient experimentation policies. Regulation and Governance, doi: 10.1111/rego.12375.

Poort, L. M. (2013). Consensus and controversies: An interactive legislative approach to animal biotechnology in Denmark, Switzerland, and the Netherlands (Dissertation Tilburg University). The Hague: Eleven International Publishing.

Ranchordás, S. (2013). The whys and woes of experimental legislation. The Theory and Practice of Legislation, 1(3), 415-440.

Ranchordás, S. (2015). Innovation-friendly regulation: The sunset of regulation, the sunrise of innovation. Jurimetrics, 55, 201-224.

Ranchordás, S. (2018). One foot in the door: Evidence-based limits on the legislative mandate. University of Groningen Faculty of Law Research Paper Series 11/2018, 1-39, https:// ssrn.com/abstract=3159026.

Stokes, E. (2012). Nanotechnology and the products of inherited regulation. Journal of Law and Society, 39(1), 93-112.

The Federalist Society 2011 National Lawyers Convention. (2012). Showcase Panel IV: A Federal Sunset Law. Texas Review of Law and Politics, 16(2), 339-366.

Van der Knaap, P. (2004). Theory-based evaluation and learning: Possibilities and challenges. Evaluation, 10(1), 16-34.

Van der Meer, P., Angenon, G., Bergmans, H., Buhk, H. J., Callebaut, S., Chamon, M., ... \& Zimny, T. (2021). The status under EU law of organisms developed through novel genomic techniques. European Journal of Risk Regulation, doi.org/10.1017/err.2020.105.

Van Gestel, R. A. J. \& Van Dijck, G. (2011). Better regulation through experimental legislation. European Public Law, 17(3), 539-553.

Van Twist, M., Kort, M. \& Van der Stee, M. (2015). Assessing and appraising the effects of policy for wicked issues: Including unforeseen achievements in the evaluation of the district policy for deprived areas in the Netherlands. International Journal of Public Administration, 38(8), 596-605.

Visser, M. \& Van der Togt, K. (2016). Learning in public sector organizations: A theory of action approach. Public Organization Review, 16, 235-249.

Wesseler, J. \& Purnhagen, K. (2021). Is the Covid-19 pandemic a game changer in GMO regulation? EuroChoices, 19(3), 49-52. 